\title{
Kinematic traits of an elite Paralympic karateka: a case study
}

Journal: The Journal of Sports Medicine and Physical Fitness

Paper code: J Sports Med Phys Fitness-10141

Submission date: July 1, 2019

Article type: Case Report

Files:

1. Reply letter to comments on the manuscript

Version: 3

Description: Reply to reviewers

File format: application/vnd.openxmlformats-officedocument.wordprocessingml.document

2. Manuscript

Version: 2

Description: manoscritto revisionato

File format: application/vnd.openxmlformats-officedocument.wordprocessingml.document

3. Figures 1

Version: 2

Description: figura 1

File format: image/jpeg

4. Figures 2

Version: 2

Description: figura 2

File format: image/jpeg 
Dr. Alberto Oliaro

Editor

The Journal of Sports Medicine and Physical Fitness

Dear Dr. Oliaro,

Please find enclosed the revised version of the manuscript J Sports Med Phys Fitness-10141 entitled "Kinematic traits of an elite Paralympic karateka: a case study."

We thoroughly considered all the comments of the Reviewers, and we revised the current version of the manuscript. In the following, we provide a description of thic changes introduced, which are also highlighted in the manuscript.

We would like to thank you and the Reviewers for the time and experisedevoted to improving the quality of our manuserript Itrust that this revised version will be suitable for publication in The Journal of Sports Medicine and Porsican fintiness.

Best regards,

Chiarella Sforza? 


\section{\# Reviewer 1 \\ R1.1 Major corrections (main criticisms)}

Here are several major concerns: (1) The participant performed a traditional Shotokan karate - KATA which is a standardized sequence of karate movements. The some parameters from CoM and knee were analyzed. Those parameters are critical factors to KATA? It needs solid evidence-based support.

We would like to thank the Reviewer for his/her precious suggestions.

We thoroughly reconsidered the main passages of the Discussion and Introduction, as marked in the text. As suggested, we added in the Introduction a paragraphGontaining information about the critical factors for Kata performance, that on a biofsechanical perspective include also those mentioned by the Reviewer. These data are supported by previously published studies.

R1.2 (2) Those parameters were analyzed from which karate movenent of KATA? which movement phase?

We agree that the data extraction flow was not clear and sve thank the Reviewer for the chance to clarify this point. Wenow addec details about the computation of kinematic data in the Procedures section. Moreover. we afded in the Discussion some features regarding relevant outcomes for knee kinematics in particular step of the sequence.

R1.3 (3) Kumite and Kata are two types of karate. The scoring requirements and critical factors are very different between Kumite and Kata. However, some literatures on Kumite also cited int hise discussion.

The point raised by the Reviewer is correct. However, the studies we included addressed both kata and kumite athletes (references \#2 and \#5) in order to highlight the relevance of dynamic postural control during the execution karate techniques. In such papers, the importance of the achievement of a adequate technique (also in terms of biomechanical parameters) is addressed, and its role in the obtainment of a high-level performance is discussed.

\section{\# Reviewer 2}

Major corrections (main criticisms) 
R2.1 The usage of expressions as "reduced" or "decreased" (see detailed comments) are inappropriate and should be replaced throughout. However, I feel some speculations on practical consequences or specific recommendations would enhance the value for the reader. All the areas where the manuscript needs further improvement have been pointed in the specific comments.

We would like to thank the Reviewer for his/her precious suggestions. We thoroughly checked the manuscript and clarified all the potentially misleading expressions. As prompted by this suggestion, we also added some practical outcomes and recommendations that could provide useful insights for the reader.

R2.2 Minor corrections (page, paragraph, line where the author must maise the corrections)

Page 2, Line 7: replace "study is" with "study was"

Fixed as suggested by the Reviewer.

R2.3 Page 2, Line 16: Please delete "traditional".

This word was deleted as suggested by the Reviever.

R2.4 Page 2, Line 16: Please delete "Shotekan" Pdoubling).

Thank you for noticing the typo. We deleted the doubling.

R2.5 Page 2, Line 20: replace "more" with "longer"

Corrected as suggested by the Reviewer.

R2.5 Page 2, Line 22: replace "decreased" with "lower"

Corrected as suggested by the Reviewer.

R2.6 Page 2, Line 27: replace "reduced" with "lower"

Corrected as suggested by the Reviewer.

R2.7 Page 3, Line 9: change "incoming" into "upcoming"

Changed as suggested by the Reviewer.

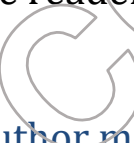


R2.8 Page 3, Line 12: change "involving a sequence" into "involving sequences" Changed as suggested by the Reviewer.

R2.9 Page 3, Lines 28-30: This is also true for the non-paralympic games, I guess. The point raised by the Reviewer is correct. We focused only on the Paralympic Program to highlight the lack of international recognition for top level competitions of parakarate. However, if the Reviewer believes that adding a reference to able-bodied competitions should clarify the context for the reader, we are open to add more details.

R2.10 Page 3, Line 53: change "Participants" into "Participant

We made the change as suggested by the Reviewer.

R2.11 Page 4, Lines 14-16: What does "5/6" or / 3/4" mean in this context?

The Paralympic karateka trained 5 to 6 times per week before and 3 to 4 times per week after the operations. We agreed that there was a lack of glarity. We sentence by replacing "/" with "to".

\section{R2.12 Page 4, Line 29: Which kata was perforned?}

As stated, the kata was the same of the previous stidy (reference \#14) taken as a comparison with able-bodied athleters. We intentionally didn't report the entire sequence of movements to avoid redurancy. However, if the Reviewer believes that adding the description of the whole sequence of movement should be useful for the reader, we are availabje to add the details of kata performed.

\section{R2.13 Page 4, Line 37: What does "advancement" means? "in front"? "forwards"?}

We acknowledge that passage was not as clear as we intended. We added "forward" before "advancement" to clarify the direction of the movement.

\section{R2.14 Page 5, Line 43: replace "reduced" with "lower"}

Replaced as suggested by the Reviewer.

R2.15 Page 6, Line 29: replace "decreased" with "was lower"

Replaced as suggested by the Reviewer. 
1

2

R2.16 Page 7, Line 13: What does "decreasing" mean in this context?

Thanks for the question. We replaced "decreasing" with a more consistent expression to highlight physical impairments negative effects.

\section{R2.17 Page 9, Lines 19-21: Please correct citation \#5.}

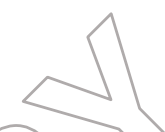

Thanks for noticing the error. We corrected the citation adding the missing details.

R2.18 Figures 1 and 2: The resolution of the figures should be improved. Why didyou report the median instead of the mean with 95\% confidence intervals? We now exported the figures at higher resolution.

Thanks for noticing the typo. We replaced "median" with "mean". 


\section{Kinematic traits of an elite Paralympic karateka: a case study}

Authors: Filippo BERTOZZI ${ }^{1 \#}$, Matteo ZAGO ${ }^{1,2 \#}$, Daniela CIPRANDI ${ }^{1}$, Christel GALVANI ${ }^{3}$, Chiarella SFORZA ${ }^{1,4^{*}}$

Authors affiliations: ${ }^{1}$ Department of Biomedical Sciences for Health, Università degli Studi di Milano, Milan, Italy; ${ }^{2}$ Department of Electronics, Information and Bioengineering (DEIB), Politecnico di Milano, Milan, Italy; ${ }^{3}$ Department of Psychology, Univerisità Cattolica del Sacro Cuore, Milan, Italy; ${ }^{4}$ Institute of Molecular Bioimaging and Physiology, National Research Council, Segrate, Italy

\#Dr Bertozzi and Dr Zago equally contributed to this study

\section{*Corresponding author:}

Prof. Chiarella Sforza, MD

Dipartimento di Scienze Biomediche per la Salute, Universita degli Stadodi Milano

Via Mangiagalli 31, 20133, Milan, Kialy

chiarella.sforza@unimi.it

Abstract word count: 215

Text-only word count: 1920

Number of figures and tables: 2 figures; 1 tabies

Number gif references. 26 


\begin{abstract}
Karate is a martial art that include striking, kicking and punching techniques, demanding and requires high levels of functional abilities skills. Karate counts millions of practitioners worldwide and it is also spreading in Paralympic competitions, requiring: there is a need for accurate categories definition for disabled athletes. The aim of the present current study is was to present kinematic data of an elite Paralympic karateka, in comparison with able-bodied athletes, to promote a better classification within the discipline; based on objectiye evaluations of physical impairments. A male black belt Paralympic karateka (age: 36 years; body weight: $75.5 \mathrm{~kg}$; height: $173 \mathrm{~cm}$ ) with lower limbs impairments was evaluated. He performed a standardized sequence of movements (kata) from traditional Sh tokan karate Shofokg. Joints and center-of-mass kinematics were collected with an optoelectronic motiog capture system and compared with those obtained in two groups of abre-bodied (Masiers and Practitioners) athletes from a previous study. The sequence performed by the karateka lasted more longer than in both able-bodied groups. Center of mass yelocity and aceereration decreased lowered in comparison with Masters. Knees range of movement and peak angdapiaclocity were similar to Practitioners but lower than Masters. We conclinded that fise physical impairments negatively affected the function of lower limbs in the Paraly in karate elite performance dynamic balance control and joint angular velocity) were reduced lower.
\end{abstract}

Keywords: martial arts, adapted phssical activing, sport biomechanics, disability, motion capture.

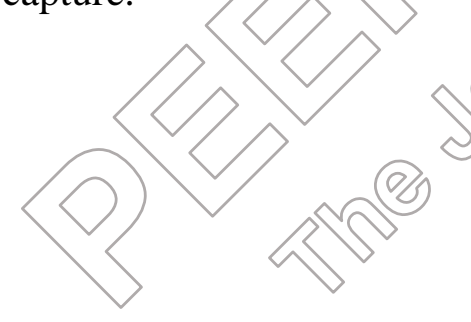




\section{INTRODUCTION}

Karate is a Japanese martial art that originated in the island of Okinawa and spread worldwide following World War II. Nowadays the World Karate Federation (WKF) claims that Karate has more than 100 million practitioners in 194 national federations around the world. Moreover, the International Olympic Committee (IOC) has recently included karate competitions as an additional sport in the ineoming upcoming Tokyo 2020 Olympic Games program.

Karate competition consists of kumite, competitive sparring, and kata, an exhibition of forms involving a sequence sequences of offensive and defensive movements targeting a virtual opponent ${ }^{1}$. These movements include mainly striking, kicking and punching techniques and require high levels of functional and motor abilities ${ }^{2}$. During a conventional fight system, conducted within a sustained endurance regimen, the karateka highiy increase heir ventilation and blood pressure ${ }^{3}$. Furthermore, continuative karate training improses physical qualities including flexibility, strength, balance and cardigrespiratory fitness ${ }^{4}$

Recently, consideration for adapted physical activity (APA) for people with physical or cognitive impairments increased, alongside with the inclusion of Paraympic disciplines in national sport federations. In addition, some studies regaring elire Paralympic athletes have been published ${ }^{8-12}$.

To date, among oriental martial arts, onily Judo aind Taekwondo entered the Paralympic Games program. However, WKF has been workingsince 2000 io create para-karate, with competitions involving athletes with various disabilities. In 20 s $5 \mathrm{~W}$ KF has also been recognized as a member by the International Paralympic Coommittee.

Biomechanical analyses can higblight the residual functional ability of athletes and provide an evidence-based classification in Paralympic sports, showing how physical impairments inflence activity and sport performance ${ }^{13}$. One of the main factor affecting performance in kata competition is dynamic postural control, represented by the kinematic analysis of the body Center of Mass $(\mathrm{CoM})^{2,5,14,15}$. Information about CoM displacement, velocity and acceleration during Karate techniques execution offer a general description of whole-body movements and reflects athletes' ability and experience ${ }^{1,15-17}$.

Moreover, some studies identified knee movements as crucial factors for enhancing performance in both punching and kicking kata techniques ${ }^{18-21}$.

HoweverDespite the determinants of kata performance were extensively discussed in the actual body of literature, no studies currently reported data regarding the biomechanics of Paralympic karate. In fact, some studies reported differences between elite athletes and practitioners ${ }^{13,14}$, 
but to date no one has presented a comparison between high level Paralympic and able-bodied karateka.

Therefore, the purpose of this study was to evaluate body kinematics of an elite Paralympic karateka (national champion), comparing his data to those collected in a previous study conducted on able-bodied karateka ${ }^{15}$.

The findings of this work could be useful both for karate coaches and physigar therapists in improving their training and rehabilitation strategies for Paralympic athletes

\section{CASE REPORT}

\section{$\underline{\text { Participants }}$}

Kinematic assessment was accomplished on a 36-year-old male black belt Paraympic karateka (body weight: $75.5 \mathrm{~kg}$; height: $173 \mathrm{~cm}$ ). He was a member of Federazione Italiana Judo Lotta Karate Arti Marziali (FIJLKAM, affiliated to WKF) and national champion of para-karate individual kata. Furthermore, he took part in severai internationapompetitions of para-karate. His physical disability was caused by complications after surgical operaitions, due to tendons laxity in his lower limbs. At the moment of evaluation the maininipairment was a complete bilateral gastrocnemius and soleus atrophy, that caused a notable decrease in knee and ankle mobility and force output. The athlete had been performing high level karate for 20 years before the disability took place, with $5 t$ to 6 tranimg sessions per week. After the post-operative rehabilitation, he aitended 3 to 4 sessions of parassarate training per week.

The karateka signed an informed writen consent, the study was approved by the local Ethics committee and met the current ethical standards in sports and exercise research, according to Helsinki Declaration.

Kinematic parameters were compared to those from obtained in a previous study investigation, conducted with analogous procedures on 10 able-bodied black belt karateka divided in two groups: Masters (elite karateka, members of the Italian national team), and Practitioners (nonelite, amateurs karateka) $)^{1,15}$.

\section{Procedures}

The karateka performed seven repetition of the same kata performed in of the previous study, defined by an experienced Master of Shotokan karate, to allow a comparison with ablebodied athletes. In short, movements composing the sequence of 11 steps were chosen among the fundamental techniques of traditional Shotokan karate ${ }^{15}$. Before trials, the karateka warmed up with his coach. The sequence was performed at maximum effort; between repetitions, full recovery was conceded. 
The 11-steps sequence was performed along three directions (forward advancement, right backward displacement and left advancement) and included advancement and backward positions, blocks, punches, and a circular kick with the left leg.

Twenty-three body markers (diameter: $15 \mathrm{~mm}$ ) were placed on the skin at the following landmarks: right and left tragion, acromion, olecranon, radius styloid process, anterosuperior iliac spines, great trochanter, femoral lateral epicondyle, lateral malleolus, heed, toe, glabella, spinous process of the $7^{\text {th }}$ cervical vertebra, sacrum. The three-dimensional coordinates of each landmark were recorded at $120 \mathrm{~Hz}$ by an optoelectronic motion capture system(BTS Smart-E, Milano, Italy). The markers coordinates were filtered with a $15 \mathrm{~Hz}$, low-pass, ind order Butterworth filter. The 11 events linked defining the timing of to each kata techinque were manually located using the motion capture software. Sequence duration was cagulated between the first and the last event.

Knee flexion angles were computed under the simplifying assumption of 1-degree-of-freedom joints. Angular range of motion (RoM) during the seculence andpeak angular velocity were obtained to provide a complete joints motion description.

body Center of Mass $\theta$ CoM coordinates were estimated using the Segmental Centroid

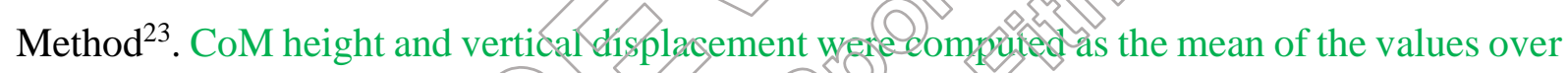
the entire kata and normalized to the body height. Horizontal displacement was expressed as the sum of all movements of the CoM projection on trieehorizontal plane. CoM average velocity was calculated over the whole sequenge, as well $\mathrm{es}$ CoM acceleration, expressed by the root mean square (rms) of the relative track.

Statistical analysis

Each kinematic parameter regarding the Paralympic karateka was expressed as the mean over triais. Kinematic variadies for Masters and Practitioners were presented as group mean together with $95 \%$ confidence intervals (CI). To assess differences between Paralympic karateka and able-bodied groups, the one-sample t-tests were performed. The Significance level was set at $5 \%(\mathrm{p}<0.05)$.

\section{RESULTS}

The duration of the kata sequence performed by the karateka was significantly longer than those of both Masters and Practitioners (6.51 s vs. 3.33 s, p<0.001 and 3.96 s, p=0.012 respectively). Table 1 lists CoM and knee kinematics data of Paralympic karateka compared with able-bodied groups. 
Figures 1 and 2 show CoM and knee kinematics results. Masters and Practitioners data are displayed as percentage increment or decrement from the Paralympic karateka mean values, taken as reference, together with $95 \%$ CIs.

When compared to elite karateka, CoM average velocity was $73 \%$ lower $(\mathrm{p}<0.001)$ and acceleration was $21 \%$ lower ( $\mathrm{p}=0.053$ ). Additionally, knee RoM and peak angular velocity were significantly reduced lower, except for right knee RoM.

Fig. 1 - Fig. 2

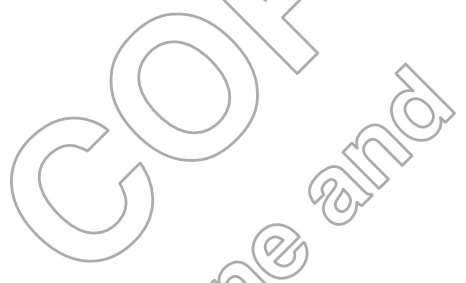

\section{DISCUSSION}

To date very few researches have been conducted on the biomechanical profile of Paralympic athletes ${ }^{13}$, and none reported quantitative biomechanical data conerning martial arts, despite their global spread. To partially fill this gap, in our study we evaluared an elite Paralympic karateka, with serious lower limb impairments, was evafuned and we compared his kinematics was compared features with those of able-bodied athletes.

\section{CoM kinematics}

In kata, likewise the correct execution of techniques, balance control represents the main performance factor for athletes' evalgation $2,5,15$. The karateka's dynamic balance should be maintained during constant and rapid movements.

Dynamic balance has been demonstrated to be strongly related with CoM position and displacement ${ }^{24}$. In Paralympic karateka, lower limb impairments could influence CoM displacement, velocity and acceleration, affecting the whole-body postural control.

The current study revealed that the duration of the sequence performed by the karateka was considerably longer than that of healthy Masters and Practitioners. We ean hypothesize that a complex sequence of movement, such as the selected kata, requires more time to be executed by a disabled athlete. Indeed, lower limb impairments can modify patterns of movement and decrease the velocity of displacements, consequently increasing the time required to perform the whole sequence.

CoM height and vertical displacement were similar to those of elite athletes: the karateka preserved his ability to control static balance adjustments. On the other hand, CoM average velocity and acceleration decreased were lower. Since the angular acceleration is theoretically proportional to the resultant torque power at the joint, this trait is probably the consequence of 
the powerlessness inability of calf muscular area to express normal moments of force levels of power. Therefore, dynamic balance together with the ability of moving the CoM in space with a high-power rate could be negatively affected.

\section{$\underline{\text { Knee kinematics }}$}

In karate, techniques are performed much faster than in any other martial $\operatorname{arts}^{3}$, requiring high levels of speed and agility ${ }^{2}$. A high grade of muscular power is needed during kicking actions. Moreover, elevate joints angular velocities during these movements are essential features for elite karateka ${ }^{25}$.

Considering that the knee was the joint mainly affected by the disability, notable differences were expected. RoM values for both knees were similar between the Paralympic Karateka and Practitioners, also taking the great variability of amateurs'paraneters into accojnt. Comparing the same parameters with Masters', a decrease of $12 \%$ for both knees occurred. In particular, considering step 4, a transitional phase from a forky ard punch to a biodking technique using the left limb as a single support, the right knee ryas considerables less flexed than both in Practitioners and Amateurs. Since the karateka executed the movere during a unipedal stance, it should be reasonable that the kneel of the swinging leg was fess flexed to maintain the right foot closer to the base of support. This could bea strastegy to oppose the loss of control during the single limb stanee, probably due to the weakness of the support leg.

Analyzing Concerning the peak angular verocity, we gan notice the same behavior of RoMs. Besides a high variablity, the Paralgmpic karafoka had quite similar results compared to Practitioners, while he showed clear reduction of his physical performance when a comparisøn with Masters was done. Bearing in mind the similar exposure to practice (20 vs. 17 years $)^{15}$, we can state that the strong reduction of calf muscular tissue had negatively affected the pepformance, entaing reduction of RoMs and slowness of knee movements.

Knee kinematics is crucial in high level kata punching and kicking techniques ${ }^{18-21}$. Thus, a recommended purpose for physical therapists and karate coaches, working with Paralympic athletes, should be to recover, as much as possible, acceptable levels of strength and RoM at the joint. Exercises improving joint mobility, during rehabilitation phase and practices, should allow to increase knee flexion and thus maintain CoM lower during movements, enhancing dynamic balance. Moreover, trainers should aim to retrieve leg extensors muscular strength, preserving at the same time a normal hamstrings-to-quadriceps ratio to avoid injuries and asymmetries $^{26}$.

The study has some limitations. Firstly, the peculiarity of the athlete's physical impairments has not allowed a collection of data on a larger sample. Moreover, we didn't measure muscular 
force output or muscular activation. Finally, to compare the karateka's values with data from the previous study, some joints were excluded from kinematic computations.

\section{CONCLUSION}

In this study, whole body kinematics of a Paralympic elite karateka was analyzed and compared to the same parameters of able-bodied athletes. The physical impairments of the assessed athlete negatively affected his $\theta$ lower limbs function in the karateka, decreasing negatively altering key factors for kata performance, like dynamic balance control and knee joints RoMs and angular velocity.

Since Paralympic categorization for karate is already in process, this \&ase report could support a better classification and encourage further biomechanical studies on disablediathletes.

\section{NOTES}

\section{Acknowledgements}

The authors warmly thank Alessio Castellano for his participationand Mauro Frustagli for his precious suggestions.

\section{Disclosure}

The authors have no conflicts of interest to declare

\section{Authors' contributions}

All authors meet the criteria for authorship established by the International Committee of Medical Journal Editors. 


\section{REFERENCES}

1. Zago M, Codari M, Iaia FM, et al. Multi-segmental movements as a function of experience in karate. J Sports Sci 2017; 35: 1515-1522.

2. Filingeri D, Bianco A, Zangla D, et al. Is karate effective in improving postural control? Arch Budo 2012; 8: 203-206.

3. Arus E. Biomechanics of Human Motion: Applications in the Martial Arts: Second Edition. 2nd Editio. Boca Raton, Florida: CRC Press, Taylor \& Francis. Epub ahead of print 9 November 2017. DOI: 10.1201/b22446.

4. Violan MA, Small EW, Zetaruk MN, et al. The Effect of Rarate Training on Flexibility, Muscle Strength, and Balance in 8- to 13-Year-Oid Boys. Podiatr Exerc Sci 1997; 9: 55-64.

5. Gauchard GC, Lion A, Bento L, et al. Postural control in high-ievel kata and kumite karatekas. Mov Sport Sci - Sci Mot 2018; 109: 21-26.

6. Origua Rios S, Marks J, Estevan I, et al. Healh benefits of hard nartial arts in adults: a systematic review. J Sports Sci, 2018, 36: 1614-1622.

7. Mastnak W. Karate-based prevention of work-related musculoskeletal syndromes: a study on the possible benefits of martialaids in sports medicine and for occupational health. Sport Sci Health 2017; 13: $1-8$.

8. Brickley $\mathrm{G}_{2}$ Gregsen HC. A Case Study of Paralympic Cerebral Palsy Cyclist Using Torque Analysis. Int J Sparis Sci Coder 2011; 6: 269-272.

9. Boyd C, Barnes C, EavessJ, et al. A time-motion analysis of Paralympic football for athletes with cerebrab palsy. Int J Sports Sci Coach 2016; 11: 552-558.

10. Bednarczuk G, Molik B, Morgulec-Adamowicz N, et al. Static balance of visually impaired paralympic goalball players. Int J Sports Sci Coach 2017; 12: 611-617.

11. Cavaggioni L, Trecroci A, Tosin M, et al. Individualized dry-land intervention program for an elite Paralympic swimmer. J Sports Med Phys Fitness 2018; 59: 82-86.

12. Mashkovskiy E, Magomedova A, Achkasov E. Degree of vision impairment influence the fight outcomes in the Paralympic judo: a 10-year retrospective analysis. J Sports Med Phys Fitness 2019; 59: 376-379.

13. Morriën F, Taylor MJD, Hettinga FJ. Biomechanics in Paralympics: Implications for Performance. Int J Sports Physiol Perform 2017; 12: 578-589.

14. Cesari P, Bertucco M. Coupling between punch efficacy and body stability for elite karate. J Sci Med Sport 2008; 11: 353-356. 
15. Zago M, Mapelli A, Shirai YF, et al. Dynamic balance in elite karateka. $J$ Electromyogr Kinesiol 2015; 25: 894-900.

16. Zago M, Motta AF, Mapelli A, et al. Effect of leg dominance on the center-of-mass kinematics during an inside-of-the-foot kick in amateur soccer players. J Hum Kinet 2014; 42: 51-61.

17. Zago M, Piovan AG, Annoni I, et al. Dribbling determinants in sub-elite-youth soccer players. J Sports Sci 2016; 34: 411-419.

18. Rinaldi M, Nasr Y, Atef G, et al. Biomechanical characterization of the Junzuki karate punch: indexes of performance. Eur J Sport Sci 2018; 18: 796-805.

19. Camomilla V, Sbriccoli P, di Mario A, et al. Comparison of two variants of A Rata technique (Unsu): The neuromechanical point of view. J Sport Sci Mectogo09; 8: 29-35.

20. Lenetsky S, Harris N, Brughelli M. Assessment and contributors \&f punching forces in combat sports athletes: Implications for strength and conditioning. Strength Cond $J$ 2013; 35: 1-7.

21. Loturco I, Artioli GG, Kobal R, etan. Rredicting punching acceteration from selected strength and power variables in elite karate athletes: A multipue regression analysis. $J$ Strength Cond Res 2014; 28:1826-1832.

22. Pozo J, Bastien G, Dierick F. Exxecution Gime, kinetics, and kinematics of the mae-geri kick: Comparison of national and internationafstandard karate athletes. J Sports Sci 2011; 29: 1553-1561.

23. Mapelli A, Zago M, Fusini Set al Kaidation of a protocol for the estimation of threedimensional body center of mass kinematics in sport. Gait Posture 2014; 39: 460-465.

24. Teixeira LA, de Oliveira DL, Romano RG, et al. Leg preference and interlateral asymmetry off balance stability in soccer players. Res Q Exerc Sport 2011; 82: 21-27.

25. Sforza C, Turci M, Grassi GP, et al. Repeatability of mae-geri-keage in traditional karate: a three-dimensional analysis with black-belt karateka. Percept Mot Skills 2002; 95: 433-444.

26. Kim D, Hong J. Hamstring to quadriceps strength ratio and noncontact leg injuries: A prospective study during one season. Isokinet Exerc Sci 2011; 19: 1-6. 


\section{TABLES}

Tabble 1: Paralympic Karateka kinematic values (mean \pm SD) and statistical significance (one-sample t-test) of differences with able-bodied groups

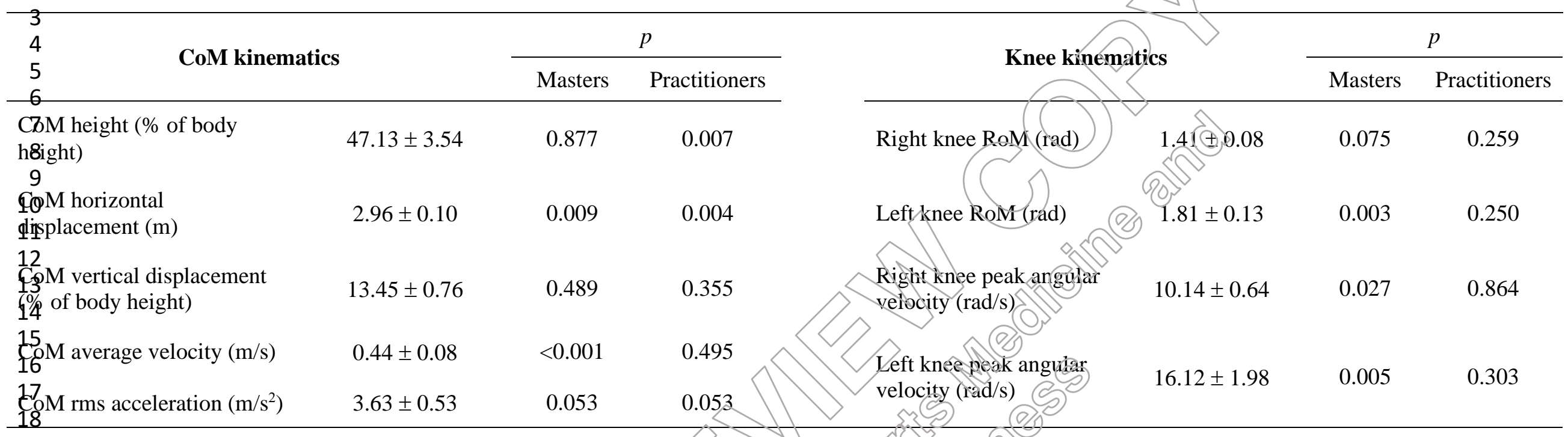

19

20

21

22

23

24

25

26

27

28

29

30

31

32

33

34

A3breviations: CoM, center of mass; RoM, range of motion; rms, root mean square

36

37

38 


\section{TITLES OF FIGURES}

Figure 1 Median Mean of Masters (circles) and Practitioners (squares) and 95\% Confidence Intervals (bars) relative to the percentage change of CoM kinematic variables, taking the Paralympic karateka values as reference $(0 \%)$. Negative values express a decrease while positive values express an increase, compared to Paralympic karateka values

Figure 2 Median Mean of Masters (circles) and Practitioners (squares) and 950 Confidence Intervals (bars) relative to the percentage change of knee kinematic variables, taking the Paralympic karateka values as reference $(0 \%)$. Negative values express a decrease while positive values express an increase, compared to Paralympic karateka values 
Kinematic traits of an elite Paralympic karateka: a case study

Authors: Filippo BERTOZZI ${ }^{1 \#}$, Matteo ZAGO ${ }^{1,2 \#}$, Daniela CIPRANDI ${ }^{1}$, Christel GALVANI ${ }^{3}$, Chiarella SFORZA ${ }^{1,4^{*}}$

Authors affiliations: ${ }^{1}$ Department of Biomedical Sciences for Health, Università degli Studi di Milano, Milan, Italy; ${ }^{2}$ Department of Electronics, Information and Bioengineering (DEIB), Politecnico di Milano, Milan, Italy; ${ }^{3}$ Department of Psychology, Univerisità Cattolica del Sacro Cuore, Milan, Italy; ${ }^{4}$ Institute of Molecular Bioimaging and Physiology, National Research Council, Segrate, Italy

${ }^{\#}$ Dr Bertozzi and Dr Zago equally contributed to this study

\section{*Corresponding author:}

Prof. Chiarella Sforza, MD

Dipartimento di Scienze Biomediche per la Salute, Universita degli Stadodi Milano

Via Mangiagalli 31, 20133, Milan, Kaly

chiarella.sforza@unimi.it

Abstract word count: 215

Text-only word count: 1920

Number of figures and tables: 2 figures; 1 tabie

Number gif references. 26 


\begin{abstract}
Karate is a martial art that include striking, kicking and punching techniques, and requires high levels of functional skills. Karate counts millions of practitioners worldwide and it is also spreading in Paralympic competitions: there is a need for accurate categories definition for disabled athletes. The aim of the current study was to present kinematic data of an elite Paralympic karateka, in comparison with able-bodied athletes, to promote a better classification within the discipline, based on objective evaluations of physical impairments. A male black belt Paralympic karateka (age: 36 years; body weight: $75.5 \mathrm{~kg}$; height. $173 \mathrm{~cm}$ ) with lower limbs impairments was evaluated. He performed a standardized sequence of movements (kata) from Shotokan karate. Joints and center-of-mass kinematics were collected with an optoelectronic motion capture system and compared with those obtained in twogroups of ablebodied (Masters and Practitioners) athletes from a previous study. The secquence performed by the karateka lasted longer than in both able-bodied groups. Center of mass velocity and acceleration lowered in comparison with Masters. Knees range of finovement and peak angular velocity were similar to Practitioners but lower than Masters. We concluded that physical impairments negatively affected the function of lower limbs in fire Paralympic athlete, as fundamental skills in karate elite performance (dynamic balance control and joint angular velocity) were lower.
\end{abstract}

Keywords: martial arts, adapted phssical activing, sport biomechanics, disability, motion capture.

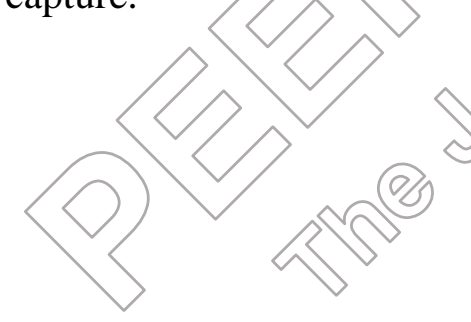




\section{INTRODUCTION}

Karate is a Japanese martial art that originated in the island of Okinawa and spread worldwide following World War II. Nowadays the World Karate Federation (WKF) claims that Karate has more than 100 million practitioners in 194 national federations around the world. Moreover, the International Olympic Committee (IOC) has recently included karate competitions as an additional sport in the upcoming Tokyo 2020 Olympic Games program.

Karate competition consists of kumite, competitive sparring, and kata, an exhibition of forms involving sequences of offensive and defensive movements targeting a virtual opponent ${ }^{1}$. These movements include mainly striking, kicking and punching techniques and require high levels of functional and motor abilities ${ }^{2}$. During a conventional fight system, conducted within a sustained endurance regimen, the karateka highly increase their ventilation and blood pressure ${ }^{3}$. Furthermore, continuative karate training improves physical qualities including flexibility, strength, balance and cardiorespiratory fitness ${ }^{4-7}$

Recently, consideration for adapted physical activity (APA) for people with physical or cognitive impairments increased, alongside with the inclusion of Paranmpic disciplines in national sport federations. In addition, some studies regaring elire Paralympic athletes have been published ${ }^{8-12}$.

To date, among oriental martial arts, onily Judo aind Taekwondo entered the Paralympic Games program. However, WKF has been workingsince 2000 io create para-karate, with competitions involving athletes with various disabilities. In 20 s $5 \mathrm{~W}$ KF has also been recognized as a member by the International Paralympic Cormmittee.

Biomechanical analyses can higblight the residual functional ability of athletes and provide an evidence-based classification in Paralympic sports, showing how physical impairments inflence activity and sport performance ${ }^{13}$. One of the main factor affecting performance in kata competition is dynamic postural control, represented by the kinematic analysis of the body Center of Mass (CoM $)^{2,5,14,15}$. Information about CoM displacement, velocity and acceleration during Karate techniques execution offer a general description of whole-body movements and reflects athletes' ability and experience ${ }^{1,15-17}$.

Moreover, some studies identified knee movements as crucial factors for enhancing performance in both punching and kicking kata techniques ${ }^{18-21}$.

Despite the determinants of kata performance were extensively discussed in the actual body of literature, no studies currently reported data regarding the biomechanics of Paralympic karate. In fact, some studies reported differences between elite athletes and practitioners ${ }^{13,14}$, but to 
date no one has presented a comparison between high level Paralympic and able-bodied karateka.

Therefore, the purpose of this study was to evaluate body kinematics of an elite Paralympic karateka (national champion), comparing his data to those collected in a previous study conducted on able-bodied karateka ${ }^{15}$.

The findings of this work could be useful both for karate coaches and physical therapists in improving their training and rehabilitation strategies for Paralympic athletes.

\section{CASE REPORT}

\section{$\underline{\text { Participant }}$}

Kinematic assessment was accomplished on a 36-year-old male black belt Paraympic karateka (body weight: $75.5 \mathrm{~kg}$; height: $173 \mathrm{~cm}$ ). He was a member of Federazione Italiana Judo Lotta Karate Arti Marziali (FIJLKAM, affiliated to WKF) and national champion of para-karate individual kata. Furthermore, he took part in severai internationaloompetitions of para-karate. His physical disability was caused by complications after surgical operaions, due to tendons laxity in his lower limbs. At the moment of evaluation the mainiripairment was a complete bilateral gastrocnemius and soleus atrophy, that caused a notable decrease in knee and ankle mobility and force output. The athlete had been performing high level karate for 20 years before the disability took place, with 5 to 6 trainiring sessions per week. After the post-operative rehabilitation, he attended 3 to 4 sessions of parainarate training per week.

The karateka signed an informed witten consent, the study was approved by the local Ethics committee and met the current ethical standards in sports and exercise research, according to Helsinki Declaration.

Kinematic parameters were compared to those obtained in a previous investigation, conducted with analogous procedures on 10 able-bodied black belt karateka divided in two groups: Masters (elite karateka, members of the Italian national team), and Practitioners (non-elite, amateurs karateka) $)^{1,15}$.

\section{Procedures}

The karateka performed seven repetition of the same kata performed in the previous study, defined by an experienced Master of Shotokan karate, to allow a comparison with ablebodied athletes. In short, movements composing the sequence of 11 steps were chosen among the fundamental techniques of traditional Shotokan karate ${ }^{15}$. Before trials, the karateka warmed up with his coach. The sequence was performed at maximum effort; between repetitions, full recovery was conceded. 
The 11-steps sequence was performed along three directions (forward advancement, right backward displacement and left advancement) and included advancement and backward positions, blocks, punches, and a circular kick with the left leg.

Twenty-three body markers (diameter: $15 \mathrm{~mm}$ ) were placed on the skin at the following landmarks: right and left tragion, acromion, olecranon, radius styloid process, anterosuperior iliac spines, great trochanter, femoral lateral epicondyle, lateral malleolus, heed, toe, glabella, spinous process of the $7^{\text {th }}$ cervical vertebra, sacrum. The three-dimensional coordinates of each landmark were recorded at $120 \mathrm{~Hz}$ by an optoelectronic motion capture system(BTS Smart-E, Milano, Italy). The markers coordinates were filtered with a $15 \mathrm{~Hz}$, low-pass, ind order Butterworth filter. The 11 events defining the timing of to each kata technique were manually located using the motion capture software. Sequence duration was calculatedigetween the first and the last event.

Knee flexion angles were computed under the simplifying assumption of 1-degree-of-freedom joints. Angular range of motion (RoM) during the sequence andpeak angular velocity were obtained to provide a complete joints motion description.

CoM coordinates were estimated asing the Segmentai Centroio Nethod ${ }^{23}$. CoM height and vertical displacement were computed as the mean of the values over the entire kata and normalized to the body height. Horizontal displacement was expressed as the sum of all movements of the CoM projection on the horizontal plane. CoM average velocity was calculated over the whole sequence, as well as Con acceleration, expressed by the root mean square (rms) of the relative track

Statistical analysis

Each kinematic parameter regarding the Paralympic karateka was expressed as the mean over trais. Kinematic variables for Masters and Practitioners were presented as group mean together with $95 \%$ confidence intervals (CI). To assess differences between Paralympic karateka and able-bodied groups, the one-sample t-tests were performed. Significance level was set at 5\% $(\mathrm{p}<0.05)$.

\section{RESULTS}

The duration of the kata sequence performed by the karateka was significantly longer than those of both Masters and Practitioners (6.51 s vs. 3.33 s, $\mathrm{p}<0.001$ and $3.96 \mathrm{~s}, \mathrm{p}=0.012$ respectively). Table 1 lists CoM and knee kinematics of Paralympic karateka compared with able-bodied groups. 
Figures 1 and 2 show CoM and knee kinematics results. Masters and Practitioners data are displayed as percentage increment or decrement from the Paralympic karateka mean values, taken as reference, together with $95 \%$ CIs.

When compared to elite karateka, CoM average velocity was $73 \%$ lower $<\mathrm{p}<0.001)$ and acceleration was $21 \%$ lower ( $\mathrm{p}=0.053$ ). Additionally, knee RoM and peak angular velocity were significantly lower, except for right knee RoM.

Fig. 1 - Fig. 2

\section{DISCUSSION}

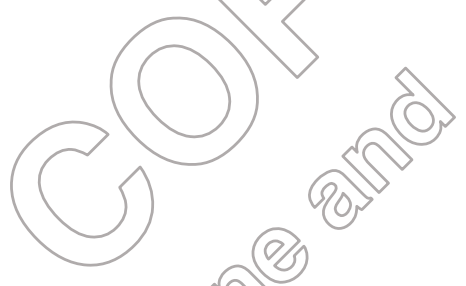

To date very few researches have been conducted on the biomechanicar profile of Paralympic athletes ${ }^{13}$, and none reported quantitative biomechanical data conererning martial arts, despite their global spread. To partially fill this gap, in our study we evaluared an elite Paralympic karateka, with serious lower limb imparments, and wercompared his kinematics features with those of able-bodied athletes.

\section{CoM kinematics}

In kata, likewise the correct execution of techniques, balance control represents the main performance factor for athletes' evalgation $2,5,15$. The karateka's dynamic balance should be maintained during constant and rapid movements.

Dynamic balance has been demonstrated to be strongly related with CoM position and displacement ${ }^{24}$. In Paralympic karateka, lower limb impairments could influence CoM displacement, velocity and acceleration, affecting the whole-body postural control.

The current study revealed that the duration of the sequence performed by the karateka was considerably longer than that of healthy Masters and Practitioners. We hypothesize that a complex sequence of movement, such as the selected kata, requires more time to be executed by a disabled athlete. Indeed, lower limb impairments can modify patterns of movement and decrease the velocity of displacements, consequently increasing the time required to perform the whole sequence.

CoM height and vertical displacement were similar to those of elite athletes: the karateka preserved his ability to control static balance adjustments. On the other hand, CoM average velocity and acceleration were lower. Since the angular acceleration is proportional to the resultant power at the joint, this trait is probably the consequence of the inability of calf 
muscular area to express normal levels of power. Therefore, dynamic balance together with the ability of moving the CoM in space with a high-power rate could be negatively affected. $\underline{\text { Knee kinematics }}$

In karate, techniques are performed much faster than in other martial arts $^{3}$, requiring high levels of speed and agility ${ }^{2}$. A high grade of muscular power is needed during kicking actions. Moreover, elevate joints angular velocities during these movements are essential features for elite karateka ${ }^{25}$.

Considering that the knee was the joint mainly affected by the disability, notable differences were expected. RoM values for both knees were similar between the Paralympic karateka and Practitioners, also taking the great variability of amateurs' parameters into account Comparing the same parameters with Masters', a decrease of $12 \%$ for both knees occured. In particular, considering step 4, a transitional phase from a forward punch to a blocking technique using the left limb as a single support, the right knee was considerably less flexed than both in Practitioners and Amateurs. Since the karateka executed the novement during a unipedal stance, it should be reasonable that the knee of the swinging leg was less right foot closer to the base of support. This could be astrategy to oppose the loss of control during the single limb stance, probably due to the weakness of the support leg.

Concerning the peak angular velocity, we can notice the same behavior of RoMs. Besides a high variability, the Paralympic karateka had quite simpilar results compared to Practitioners, while he showed a clear reduction of his physical performance when a comparison with Masters was done. Bearing in mind the simiar exposure te practice (20 vs. 17 years $)^{15}$, we can state that the strong reduction of calf museular tissue had negatively affected the performance, entailing reduction of RgMs and slowness of knee movements.

Knee kinematics is crufial in high level kata punching and kicking techniques ${ }^{18-21}$. Thus, a recommended purpose for physical therapists and karate coaches, working with Paralympic athletes, should be to recover, as much as possible, acceptable levels of strength and RoM at the joint. Exercises improving joint mobility, during rehabilitation phase and practices, should allow to increase knee flexion and thus maintain CoM lower during movements, enhancing dynamic balance. Moreover, trainers should aim to retrieve leg extensors muscular strength, preserving at the same time a normal hamstrings-to-quadriceps ratio to avoid injuries and asymmetries $^{26}$.

The study has some limitations. Firstly, the peculiarity of the athlete's physical impairments has not allowed a collection of data on a larger sample. Moreover, we didn't measure muscular 
force output or muscular activation. Finally, to compare the karateka's values with data from the previous study, some joints were excluded from kinematic computations.

\section{CONCLUSION}

In this study, whole body kinematics of a Paralympic elite karateka was analyzed and compared to the same parameters of able-bodied athletes. The physical impairments of the assessed athlete negatively affected his lower limbs function, negatively altering key factors for kata performance, like dynamic balance control and knee joints RoMs and angular velocity.

Since Paralympic categorization for karate is already in process, this case report could support a better classification and encourage further biomechanical studies on disabled athietes.

\section{NOTES}

\section{Acknowledgements}

The authors warmly thank Alessio Casteilano for his participation and Nauro Frustagli for his precious suggestions.

\section{Disclosure}

The authors have no conflicts of interest to deelare,

\section{Authors' contributions}

All authors meet the criteria for authorship established by the International Committee of Medical Journai Editors. 


\section{REFERENCES}

1. Zago M, Codari M, Iaia FM, et al. Multi-segmental movements as a function of experience in karate. J Sports Sci 2017; 35: 1515-1522.

2. Filingeri D, Bianco A, Zangla D, et al. Is karate effective in improving postural control? Arch Budo 2012; 8: 203-206.

3. Arus E. Biomechanics of Human Motion: Applications in the Martial Arts: Second Edition. 2nd Editio. Boca Raton, Florida: CRC Press, Taylor \& Francis. Epub ahead of print 9 November 2017. DOI: 10.1201/b22446.

4. Violan MA, Small EW, Zetaruk MN, et al. The Effect of Rarate Training on Flexibility, Muscle Strength, and Balance in 8- to 13-Year-Oid Boys. Podiatr Exerc Sci 1997; 9: 55-64.

5. Gauchard GC, Lion A, Bento L, et al. Postural control in high-ievel kata and kumite karatekas. Mov Sport Sci - Sci Mot 2018; 109: 21-26.

6. Origua Rios S, Marks J, Estevan I, et al. Healh benefits of hardmartial arts in adults: a systematic review. J Sports Sci, 2018, 36: 1614-1622.

7. Mastnak W. Karate-based prevention of work-related musculoskeletal syndromes: a study on the possible benefits of martialaids in sports medicine and for occupational health. Sport Sci Health 2017; 13: $1-8$.

8. Brickley $\mathrm{G}_{2}$ Gregsen HC. A Case Study of Paralympic Cerebral Palsy Cyclist Using Torque Analysis. Int J Sparis Sci Codch 2011; 6: 269-272.

9. Boyd C, Barnes C, EavessJ, et al. A time-motion analysis of Paralympic football for athletes with cerebrab palsy. Int J Sports Sci Coach 2016; 11: 552-558.

10. Bednarczuk G, Molik B, Morgulec-Adamowicz N, et al. Static balance of visually impaired paralympic goalball players. Int J Sports Sci Coach 2017; 12: 611-617.

11. Cavaggioni L, Trecroci A, Tosin M, et al. Individualized dry-land intervention program for an elite Paralympic swimmer. J Sports Med Phys Fitness 2018; 59: 82-86.

12. Mashkovskiy E, Magomedova A, Achkasov E. Degree of vision impairment influence the fight outcomes in the Paralympic judo: a 10-year retrospective analysis. J Sports Med Phys Fitness 2019; 59: 376-379.

13. Morriën F, Taylor MJD, Hettinga FJ. Biomechanics in Paralympics: Implications for Performance. Int J Sports Physiol Perform 2017; 12: 578-589.

14. Cesari P, Bertucco M. Coupling between punch efficacy and body stability for elite karate. J Sci Med Sport 2008; 11: 353-356. 
15. Zago M, Mapelli A, Shirai YF, et al. Dynamic balance in elite karateka. $J$ Electromyogr Kinesiol 2015; 25: 894-900.

16. Zago M, Motta AF, Mapelli A, et al. Effect of leg dominance on the center-of-mass kinematics during an inside-of-the-foot kick in amateur soccer players. J Hum Kinet 2014; 42: 51-61.

17. Zago M, Piovan AG, Annoni I, et al. Dribbling determinants in sub-elite youth soccer players. J Sports Sci 2016; 34: 411-419.

18. Rinaldi M, Nasr Y, Atef G, et al. Biomechanical characterizatioñ of the Junzuki karate punch: indexes of performance. Eur J Sport Sci 2018; 18: 796-805.

19. Camomilla V, Sbriccoli P, di Mario A, et al. Comparison of two variants of a Kata technique (Unsu): The neuromechanical point of view. J Sport Sci Med 2009; 8: 29-35.

20. Lenetsky S, Harris N, Brughelli M. Assessment and contributors of punching forces in combat sports athletes: Implications for strength and conditioning. Strength Cond $J$ 2013; 35: 1-7.

21. Loturco I, Artioli GG, Kobal R, et al Predicting punching acceteration from selected strength and power variables in elite karate athletes: A multipie regression analysis. $J$ Strength Cond Res 2014; 28:1826-1832.

22. Pozo J, Bastien G, Dierick F. Exxecution Gime, kinetics, and kinematics of the mae-geri kick: Comparison of national and internationafstandard karate athletes. J Sports Sci 2011; 29: $1553-1561$.

23. Mapelli A, Zago M, Fusini Let al Waidation of a protocol for the estimation of threedimensional body center of mass kinematics in sport. Gait Posture 2014; 39: 460-465.

24. Teixeira LA, de Oliveira DL, Romano RG, et al. Leg preference and interlateral asymmetry of balance stability in soccer players. Res Q Exerc Sport 2011; 82: 21-27.

25. Sforza C, Turci M, Grassi GP, et al. Repeatability of mae-geri-keage in traditional karate: a three-dimensional analysis with black-belt karateka. Percept Mot Skills 2002; 95: 433-444.

26. Kim D, Hong J. Hamstring to quadriceps strength ratio and noncontact leg injuries: A prospective study during one season. Isokinet Exerc Sci 2011; 19: 1-6. 


\section{TABLES}

Tåble 1: Paralympic Karateka kinematic values $(\operatorname{mean} \pm \mathrm{SD})$ and statistical significance (one-sample t-test) of differences with able-bodied groups

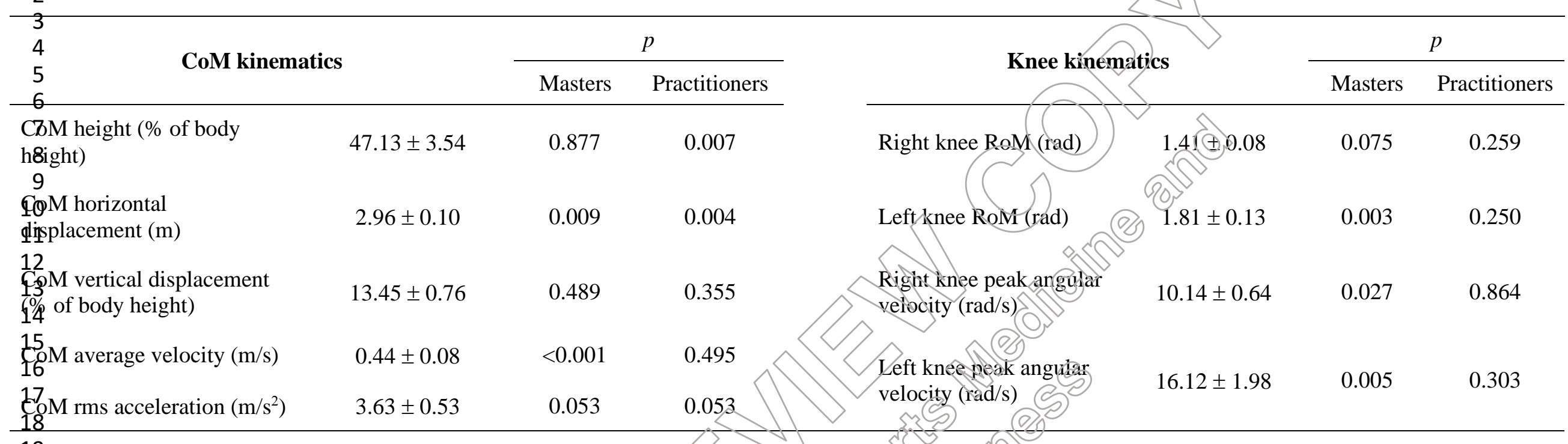

19

20

21

22

23

24

25

26

27

28

29

30

31

32

33

34

A3breviations: CoM, center of mass; RoM, range of motion; rms, root mean square

36

37

38 


\section{TITLES OF FIGURES}

Figure 1 Mean of Masters (circles) and Practitioners (squares) and 95\% Confidence Intervals (bars) relative to the percentage change of CoM kinematic variables, taking the Paralympic karateka values as reference $(0 \%)$. Negative values express a decrease while positive values express an increase, compared to Paralympic karateka values

Figure 2 Mean of Masters (circles) and Practitioners (squares) and 95\% Confidence Intervals (bars) relative to the percentage change of knee kinematic variables, taking the Patalympic karateka values as reference $(0 \%)$. Negative values express a decrease while positive values express an increase, compared to Paralympic karateka vahues 
Page 30 of 31

1

3

4

5

6

7

8

9

10

11

12

13

14

15

16

17

18

19

20

21

22

23

24

25

26

27

28

29

30

31

32

33

34

35

36

37

38

39

40

41

42

43

44

45

46

47

48

49

50

51

52

53

54

55

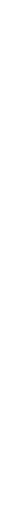

CoM rms acceleration

Case report mean values

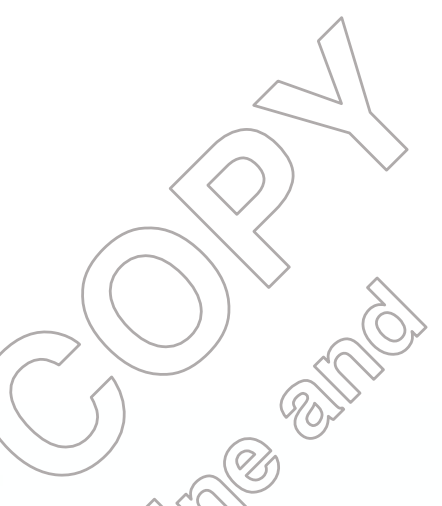

CoM average velocity

CoM vertical displacement

CoM horizontal displacement

CoM normalized height

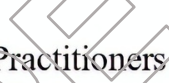

Masters

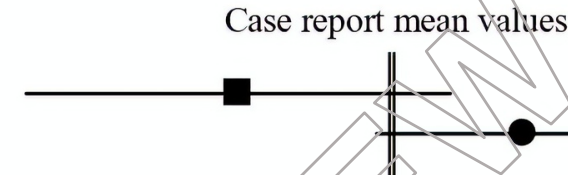

(D)
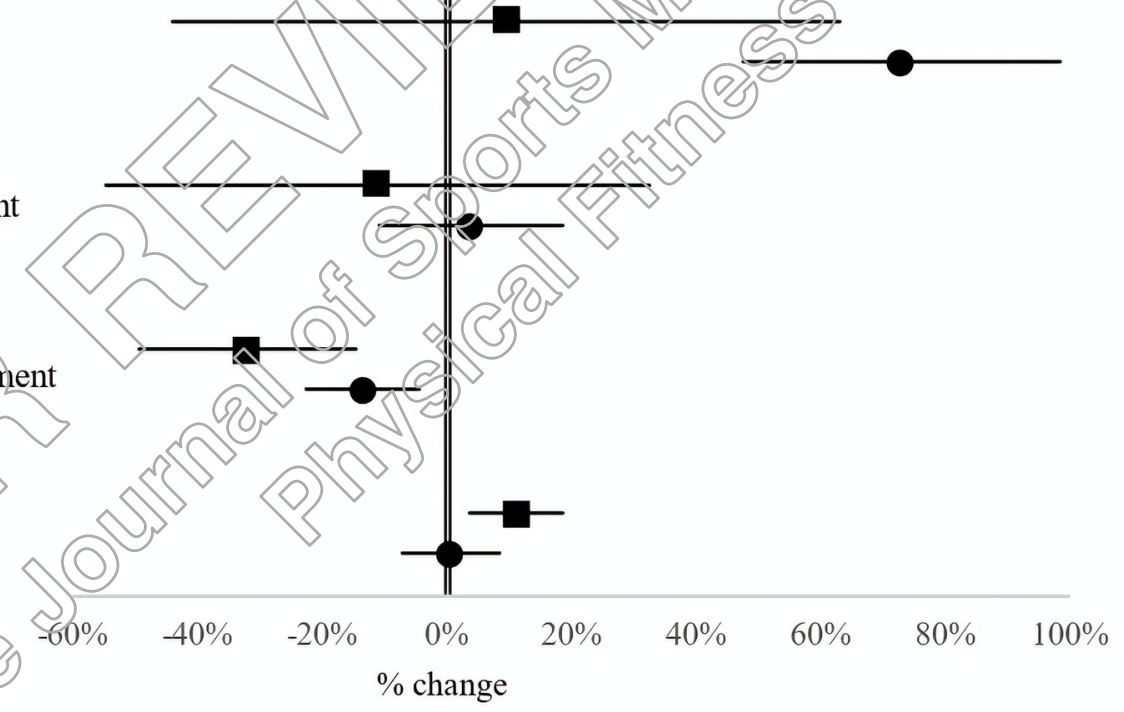
Page 31 of 31

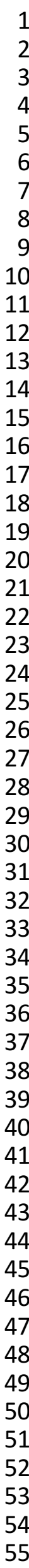

